\title{
Multiple system atrophy, parkinsonian type
}

INSERM

\section{Source}

INSERM. (1999). Orphanet: an online rare disease and orphan drug data base. Multiple system atrophy, parkinsonian type. ORPHA:98933

Multiple system atrophy, parkinsonian type (MSA-p) is a form of multiple system atrophy (MSA; see this term) with predominant parkinsonian features (bradykinesia, rigidity, irregular jerky postural tremor, and postural instability). 